\title{
THE YEAR 2021 OF THE INTERNATIONAL JOURNAL OF INNOVATION - IJI
}

\author{
Editorial comment
}

\section{Editorial comment}

(D) Isabel Cristina Scafuto Coeditor

Universidade Nove de Julho

Graduate Program in Project Management

Priscila Rezende da Costa Editor-in-Chefe

Universidade Nove de Julho

Graduate Program in Business Administration

Marcos Rogerio Mazzieri

Scientific Editor

Universidade Nove de Julho

Graduate Programs in Business Administration and in Project Management

\section{Cite as - American Psychological Association (APA)}

Scafuto, I. C., Costa, P. R., \& Mazzieri, M. R. (2021, Sept./Dec.). The year 2021 of the International Journal of Innovation - IJI. International Journal of Innovation - IJI, São Paulo, 9(3), 435-438.

https://doi.org/10.5585/iji.v9i3.21112.

The International Journal of Innovation: IJI has been making some changes in recent years and, therefore, increasingly improving its content. These are transformations that would not be possible without the incessant collaboration of the entire IJI team. Ther are always tireless and impeccable. It would not be possible without all the articles submitted by the authors who believe and choose the IJI for their publications. It would not be possible either, without the reviewers who contribute with a lot of dedication, spending their time and knowledge on improving the articles to publish the IJI. We are immensely grateful to everyone! Special thanks to UNINOVE, who have always supported and continue to support IJI. 
At the end of 2021, we would like to present some data and information that enable readers, authors, and reviewers to follow the evolution of the IJI. We remain dedicated to raising the bar for the IJI. IJI is in the main databases: Dialnet, EBSCO, ERIHPLUS, Latindex, ProQuest, Redalyc, Redib, Spell, Web of Science and Zeitschriften Datenbank. It is classified in stratum B1 of the new QUALIS/CAPES proposal. It is published every four months (January-April; May-August; September-December) and accepts submissions in Portuguese, English, and Spanish, and published in English only.

The International Journal of Innovation: IJI's mission is to serve as a vehicle for the periodic publication of scientific and technological works in innovation with a focus on emerging markets, which study individuals, organizations, ecosystems, and policies. The journal's topics of interest focusing on emerging markets are Innovative Entrepreneurship, Innovation and Learning, Innovation and Sustainability, Internationalization of Innovation, Innovation Systems, Emerging Themes of Innovation, and Digital Transformation. As we have already mentioned in another editorial comment, the IJI accepts scientific articles, technology articles, perspectives, and reviews, in addition to the editorial comment.

We now present some data from IJI submissions for this year, 2021 (Table 1).

\section{Table 1}

\section{Submissions to the IJI}

\begin{tabular}{|l|l|}
\hline Works submitted & 87 \\
\hline Rejections & $65 \%$ \\
\hline Acceptance & $35 \%$ \\
\hline
\end{tabular}

Eighty-seven works were submitted to the IJI, of which $65 \%$ were rejected and $35 \%$ were approved. With these numbers, we observe that rejection is still high. The rejection happens; most of the time, in the desk-reject the editors perform that. The reasons are: a) the submitted works are not following the scope of the IJI; b) the submitted works do not meet the minimum requirements for a publication and are not considered to proceed to a peer review and blind.

When articles move to the stage of blind and peer review, the number of rejections gets smaller. Generally, works are rejected at this stage when the authors do not comply with the evaluators' recommendations. Our intention is, with the help of reviewers and authors, to 
increasingly improve the quality of submitted articles and increase the number of publications in the IJI.

Submissions are from different countries. In this year of 2021, we had the following scenario (Table 2).

Table 2

Submissions to the IJI - by country

\begin{tabular}{|l|l|}
\hline \multicolumn{1}{|c|}{ Country } & \\
\hline Brazil & 59 \\
\hline Argentina & 1 \\
\hline Colombia & 1 \\
\hline Cuba & 1 \\
\hline Algeria & 2 \\
\hline Indonesia & 2 \\
\hline India & 3 \\
\hline Jordan & 1 \\
\hline Sri Lanka & 1 \\
\hline Mexico & 1 \\
\hline Malasia & 1 \\
\hline Nigeria & 3 \\
\hline Portugal & 2 \\
\hline Saudi Arabia & 3 \\
\hline Tunisia & 1 \\
\hline Turkey & 1 \\
\hline Ukraine & 1 \\
\hline Vietnam & 2 \\
\hline South Africa & 1 \\
\hline TOTAL & $\mathbf{8 7}$ \\
\hline & \\
\hline
\end{tabular}

The most significant works submitted are from Brazilian authors, but with a balanced distribution among other countries. We are happy that the IJI is considered a possibility for authors from different countries on our continent and other continents. We want to increase the number of foreign submissions and their publications. We believe that this action is important for the academic community due to the diversity of contexts.

The IJI counts on the valuable availability of the evaluators, who we know have to dedicate their precious time to help us improve our work. Our evaluation time is still high, up to 98 days. Some reasons impact this deadline: a) the reviewers are very demanding with 
researchers with little experience, causing back and forth in the assessments until they reach the expected quality for the article; b) holidays in the middle of the year and at the end of the year delay the evaluations a little; c) evaluators also divide their time with evaluations of academic events throughout the year. Due to these reasons, the publication of the works is also compromised. We took up to 122 days to publish the articles.

Another interesting piece of information that we would like to share with our readers is the number of registered users of IJI. IJI has 1270 registered users, including authors, reviewers, and readers. In the last year of 2021, there were 534 new users. It makes us very happy, as the number of users has almost doubled. This action makes us hope to have more works submitted and, consequently, more quality works published.

We aim to improve and make the IJI a journal with more impact in the academic and practical environment. With the help of everyone involved, we will improve the level of evaluations and significantly improve the published works. We want to bring relevant content that contributes to science in Brazil and other countries around the world.

We thank you all for your help and support in this growing IJI journey! 